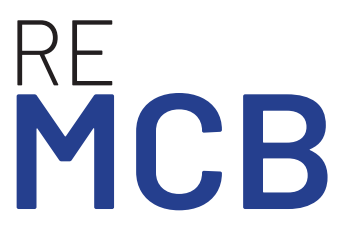

Revista Ecuatoriana de Medicina y Ciencias Biológicas

Volumen 42. No. 2, Nov. 2021

\section{Identificación de Cercospora spp. como agente causal de mancha foliar en cultivos de uvilla (Physalis peruviana L.) en la Sierra norte del Ecuador}

\author{
Identification of Cercospora spp. as causal agent of leaf spot in goldenberry \\ (Physalis peruviana L.) crops in the northern Sierra of Ecuador
}

\author{
Melany Paredes', Jeniffer Yánez ${ }^{1 *}$, Martín Marcial-Coba'
}

'Laboratorio de Fitopatología, Facultad de Ciencias Exactas y Naturales, Pontificia Universidad Católica del Ecuador, Quito, Ecuador.

*Autor de correspondencia: jyanez989@puce.edu.ec

Recibido 14-07-2021

Aceptado 26-10-2021

DOI: 10.26807/remcb.v42i2.899

e-ISSN 2477-9148

(c) 2021. Este es un artículo publicado en acceso abierto bajo una licencia CC BY-NC 4.0

Como citar este artículo: Paredes M , Yánez J. L, MarcialCoba M. 2021. Identificación de Cercospora spp. como agente causal de mancha foliar en cultivos de uvilla (Physalis peruviana L.) en la Sierra norte del Ecuador. Revista Ecuatoriana de Medicina y Ciencias Biológicas 42(2): 103-121. doi: 10.26807/remcb.v42i2.899
Resumen.- La uvilla (Physalis peruviana L.) es una planta herbácea originaria de Sudamérica. El fruto tiene un alto contenido nutricional asociado con la creciente demanda del producto a nivel nacional e internacional. Lamentablemente, el cultivo de esta planta se ha visto afectado por diversas enfermedades como la mancha foliar causada por Cercospora spp. Esta se caracteriza por presentar manchas de color marrón en las hojas y puede provocar una defoliación prematura de la planta, disminuyendo el rendimiento y la calidad del cultivo. Es por ello que esta investigación tiene como objetivo identificar a Cercospora sp. en plantas de uvilla. Para este fin, se realizó un muestreo en diferentes parcelas ubicadas en las provincias de Imbabura y Pichincha. Los aislamientos fúngicos obtenidos a partir de las lesiones compatibles con el género se caracterizaron a nivel macroscópico y microscópico. La caracterización genética de las cepas se realizó con la amplificación de los genes ITS y TEF- 1a. Las secuencias obtenidas se compararon con las bases de datos GenBank y Mycobank, donde la identidad de las cuatro cepas aisladas correspondió a Cercospora beticola. Finalmente, los postulados de Koch confirmaron que este hongo fitopatógeno es el agente causal de la mancha foliar en cultivos de uvilla.

Palabras clave: Cercospora beticola, mancha foliar, Physalis peruviana L., hongo fitopatógeno, agente causal.

Abstract.-The Goldenberry (Physalis peruviana L.) is an herbaceous plant native to South America. This fruit has a high nutritional content, which has led to increased consumption, both locally and internationally. Unfortunately, various diseases, such as leaf spot caused by Cercospora spp., have affected the cultivation of this plant. This disease produces brown spots on the leaves and can cause premature defoliation of the plant, reducing crop efficiency and quality. This research ,thus, aims to identify Cercospora sp. in goldenberry plants. Sampling was carried out in different plots located in the provinces of Imbabura and Pichincha. The strains isolated from typical lesions in plant material were characterized macro- and microscopically. The genetic characterization of the isolated strains was carried out based on amplification of the ITS and TEF-1a. The resulting sequences were compared with those deposited into the GenBank and Mycobank databases, where four strains of Cercospora beticola were identified. Finally, Koch's postulates confirmed that this phytopathogenic fungus is the causal agent of leaf spot in goldenberry crops.

Keywords: Cercospora beticola, leaf spot, Physalis peruviana L., phytopathogenic fungus, causal agent. 


\section{Introducción}

La uvilla (Physalis peruvia na L.) es una planta herbácea y perenne que forma parte de la familia Solanaceae (Fischer et al. 2021). Es originaria de los Andes sudamericanos; en especial, de Colombia, Perú y Ecuador, donde crece como una planta silvestre o semi-silvestre en zonas altas entre 1500 y 3000 m.s.n.m. (Trillos et al. 2008). Aunque también se ha confirmado la presencia de esta planta en algunos países como Kenia, Sudáfrica y Egipto, donde puede crecer en los trópicos o subtrópicos y no, exclusivamente, en condiciones frías y templadas (Fischer y Melgarejo 2020). En Ecuador crece entre 1300 a 3500 m.s.n.m, con temperaturas promedio de 13 a $15^{\circ} \mathrm{C}$ y puede alcanzar una altura de 1-1,5 metros (Fischer et al. 2014).

Physalis peruviana L. produce una fruta exótica que, cuando alcanza la madurez, presenta un sabor agridulce y posee un color amarillo-anaranjado. Su forma es redonda y su tamaño oscila entre 1,5-2,5 cm de diámetro (Giraldo et al. 2017). Además, se presenta envuelta en un cáliz, también conocido como capacho o capuchón, que protege el fruto de las condiciones climáticas extremas, enfermedades, aves e insectos hasta la madurez (Balaguera- López et al. 2014). Las temperaturas entre $13-15^{\circ} \mathrm{C}$, y la luz con una intensidad lumínica entre 1,500 y 2,000 horas luz/ año, resultan favorables para un mejor rendimiento del cultivo y frutos con mayor coloración, gran contenido de azúcares y almidones (López- Sandoval et al 2018). Esta fruta posee altos niveles de azúcar, especialmente, glucosa, sacarosa y fructosa, vitaminas A, B y C (Corrales-Bernal et al. 2015). Adicionalmente, contiene microelementos tales como fósforo, hierro, calcio, zinc y potasio, los cuales le atribuyen propiedades nutricionales y medicinales (González Cabrera et al. 2020). En función de su contenido nutricional, el consumo de uvilla se asocia con efectos antioxidantes y antiinflamatorios, que podrían tener un uso médico para el control de ciertas enfermedades como hepatitis, reumatismo y diabetes (Fischer y Melgarejo 2020).

En el Ecuador, las principales provincias dedicadas a cultivar esta fruta con fines comerciales son Cotopaxi, Pichincha, Carchi e Imbabura, las cuales representan el 74\% de la superficie de cultivos de uvilla en el país (MAG 2020). Las características nutricionales antes mencionadas se relacionan con el aumento de la demanda de uvilla a nivel nacional e internacional; especialmente, Canadá, Estados Unidos, Alemania, España y Países Bajos (Portal Frutícola 2020). Consecuentemente, las exportaciones, tanto del fruto fresco como deshidratado, se han incrementado en los últimos años. Entre el 2016 y el 2019 se evidenció un crecimiento en la exportación anual del 53,1\% de uvilla deshidratada. Además, según el Banco Central del Ecuador, en el 2019 se exportó un volumen correspondiente a 208 mil dólares de uvilla fresca (Pro Ecuador 2020). Los principales destinos de las exportaciones de uvilla en 2019 fueron: Australia (210 mil dólares), Alemania (204 mil dólares), Estados Unidos (108 mil dólares), Reino Unido (64 mil dólares) y Canadá (23 mil dólares) (Pro Ecuador 2020).

Lamentablemente, el cultivo de esta planta se ha visto seriamente afectado por diversas enfermedades causadas por microorganismos que disminuyen el rendimiento y la calidad del cultivo, generando daños significativos en la planta y provocando grandes pérdidas económicas a los productores (Catarina 2014). En Colombia, las enfermedades de mayor importancia económica son: el marchitamiento vascular causado por Fusarium oxysporum; la muerte descendente generada por Phoma spp. en ambientes que presentan alta humedad y baja temperatura; y la mancha de la hoja y el capacho, causada por Cercospora spp. Esta última es la mayor enfermedad foliar de la uvilla (Catarina 2014; Fischer et al. 2014).

El género Cercospora, perteneciente a la familia Mycosphaerellaceae, es uno de los géneros más grandes y sus especies se consideran patógenos importantes de una amplia variedad de plantas (Park et al. 2017; Rangel et al. 2020). Se reconocen 659 especies en el género Cercospora y 281 especies morfológicamente idénticas que se incluyen en el complejo Cercospora apii (Groenewald et al. 2005; Park et al. 2017). La mayoría de especies de este género no tienen una etapa sexual conocida y en las pocas especies que tienen una etapa sexual, el teleomorfo pertenece al género Mycosphaerella (Goodwin et al. 2001; Świderska-Burek et al. 2020). Las especies de Cercospora spp. se asocian con infecciones que generan manchas de las hojas y frutas en diferentes plantas cultivadas y silvestres en todo el mundo (Nguanhom et al. 2015). Los síntomas de la mancha foliar se presentan con mayor intensidad en las partes más externas e 
inferiores de la planta, aunque pueden encontrarse en cualquier parte de la hoja, como pequeñas manchas irregulares de color marrón claro o, incluso, blancas, con halos amarillos que se tornan secos y quebradizos (Tian et al. 2008). Durante las primeras etapas de la infección, el hongo posee un estilo de vida biotrófico. Sin embargo, cambian su estilo de vida a uno necrotrófico en el que se produce la muerte de la célula huésped para completar su ciclo de vida (Ebert et al. 2020).

Actualmente, en Ecuador, las investigaciones realizadas en relación a enfermedades del cultivo de uvilla son escasas. En el estudio realizado por Díaz et al. (2019) sobre hongos asociados a las manchas foliares en hojas de la uvilla, se logró aislar e identificar Cercospora sp., pero no se determinó la especie causante de la enfermedad denominada mancha foliar. Además de la limitada información referente a esta enfermedad en plantas de uvilla, las características morfológicas del fitopatógeno asociado tienen una estrecha similitud con géneros como: Corynespora spp., Pseudocercospora spp., Mycosphaerella spp., etc.; lo que dificulta aún más la identificación del género (Groenewald et al. 2013). En este contexto, el presente estudio resulta de gran interés agrícola, al proponer aislar e identificar a nivel de especie al agente causal de la enfermedad. De esta manera, se pretende que la metodología aplicada y los resultados generados en esta investigación contribuyan al establecimiento de eficientes medidas de control orientadas a la prevención y correcto diagnóstico de Cercospora spp. en cultivos de uvilla.

\section{Materiales y Métodos \\ Recolección de muestras de tejido vegetal}

El muestreo se realizó en siete localidades, pertenecientes a las provincias de Pichincha (El Tingo, San José de Minas y Aloasí) e Imbabura (Moraspungo, Huchinguero/ Alesochopa y Cumbasconde). En cada una de las parcelas, las muestras se tomaron de acuerdo con el modelo aleatorio estratificado, donde se seleccionaron las plantas con sintomatología compatible con aquella descrita brevemente arriba y que es ocasionada por la infección de Cercospora spp. en cultivos de uvilla. Con base en esto, se recolectaron las hojas con pequeñas manchas, de la zona baja, media y superior de cada planta (Tian et al. 2008).

Las hojas se colocaron en fundas de cierre hermético y fueron etiquetadas con datos correspondientes a fecha, hora, nombre de la finca y georeferencia. Las muestras se transportaron en una caja hermética a los laboratorios de la Escuela de Ciencias Biológicas de la Pontificia Universidad Católica del Ecuador para su posterior análisis en un lapso de 24 horas.

\section{Aislamiento del hongo}

Para la desinfección superficial del tejido foliar, primero se realizó un lavado de la hoja en agua potable para eliminar contaminantes presentes en la superficie. Posteriormente, se cortaron secciones de aproximadamente $1 \mathrm{~cm}^{2}$ de la zona de la hoja donde se encontraba la lesión (Farrag 2011). Inmediatamente, los fragmentos de tejido sintomático se sumergieron en alcohol etílico al 70\% durante 1 min. Luego, se colocaron en hipoclorito de sodio al 1\% durante 1 min y, finalmente, se realizaron tres lavados con agua destilada estéril (Rengifo-Guzmán et al. 2002; Agrios 2005). Los cortes de hoja desinfectados fueron secados en papel absorbente estéril y, posteriormente, se sembraron en cajas Petri conteniendo Agar Papa Dextrosa (PDA, por sus siglas en inglés) suplementado con gentamicina ( $80 \mathrm{mg} / \mathrm{L}$ ). Las cajas fueron incubadas a temperatura ambiente $\left(20\right.$ a $25^{\circ} \mathrm{C}$ ) y se observó el desarrollo de los cultivos diariamente por aproximadamente 10 días (Milosavljević et al. 2014a). Los hongos aislados con características macroscópicas similares a Cercospora spp. se purificaron en los medios PDA, Agar zanahoria (CA, por sus siglas en inglés) y Agar extracto de malta (MEA, por sus siglas en inglés) hasta conseguir un cultivo axénico en cada uno de los medios.

\section{Caracterización morfológica a nivel macroscópico y microscópico}

La descripción de la morfología a nivel macroscópico se realizó a partir de los cultivos axénicos obtenidos en los medios PDA, MEA y CA. Estos fueron incubados a $23 \pm 2^{\circ} \mathrm{C}$ durante tres semanas. Se tomó en cuenta características como textura, bordes, presencia de exudados y coloración de anverso y reverso. 
La caracterización microscópica se realizó con base en la morfología que presentaron las cepas cultivadas en medio CA por su capacidad de promover la esporulación (Chen et al. 1979). Para esto, se realizó una impronta con cinta adhesiva del micelio aéreo de la colonia fúngica, la cual se ubicó en un portaobjetos con azul de lactofenol. De forma paralela, se cortó un pequeño fragmento de la colonia fúngica con una aguja micológica y se colocó sobre un portaobjetos con agua. Las placas se observaron en el microscopio con un aumento de 400x (López et al. 2014). Las estructuras observadas fueron fascículos de conidióforos y conidios, los cuales se midieron mediante el software DinoCapture 2.0 (Mukhtar et al. 2019). Las características macroscópicas y microscópicas se compararon con fotografías y descripciones detalladas del género Cercospora en literatura científica (Agrios 2005; Crous et al. 2006; Park et al. 2020).

\section{Identificación molecular de los aislamientos fúngicos}

Se extrajo ADN a partir de los aislados fúngicos de 10 días, utilizando el kit Wizard ${ }^{\circledR}$ Genomic DNA Purification (Promega, Madison, Wisconsin, E.E.U.U. 2019). La concentración y calidad de ADN se midieron, espectrofotométricamente, usando el equipo NanoDrop 2000 (Thermo Scientific, Wilmington, Delawere, E.E.U.U. 2009).

La amplificación de las secuencias nucleotídicas de interés se llevó a cabo mediante Reacción en Cadena de Polimerasa (PCR, por sus siglas en inglés). La región ITS (espaciador transcrito interno del ADN nuclear ribosomal) fue amplificada utilizando los pares de cebadores ITS-1 (5' TCCGTAGGTGAACCTGCGG 3'), ITS-4 (5' TCCTCCGCTTATTGATATGC 3') (White et al. 1990). Los parámetros programados para esta reacción fueron: etapa de desnaturalización inicial de 1 min a $95^{\circ} \mathrm{C}$, 30 ciclos de desnaturalización a $95^{\circ} \mathrm{C}$ por 1 min, una hibridación de primers a $55^{\circ} \mathrm{C}$ por $30 \mathrm{seg}$, una elongación por $1 \mathrm{~min}$ a $72{ }^{\circ} \mathrm{C}$ y una elongación final de 5 min a $72{ }^{\circ} \mathrm{C}$. Asimismo, el gen Factor de elongación 1-alfa (TEF-1a) se amplificó con los cebadores EF1-983 (5' GCYCCYGGHCAYCGTGAYTTYAT 3'), EF1-2218 (5' ATGACACCRACRGCRACRGTYTG 3') (Rehner y Buckley 2005). La desnaturalización inicial se realizó a $94^{\circ} \mathrm{C}$ por 5 min, seguido de 30 ciclos de desnaturalización a $94^{\circ} \mathrm{C}$ por 60 seg, la hibridación de primers a $55^{\circ} \mathrm{C}$ por 60 seg, una elongación de $72{ }^{\circ} \mathrm{C}$ por 60 seg y, finalmente, una elongación a $72{ }^{\circ} \mathrm{C}$ por 4 min. Ambas reacciones tuvieron un volumen final de $25 \mu$ l, utilizando el kit comercial GoTaq ${ }^{\circledR}$ Green Master Mix (Promega, Madison, Wisconsin, EE. UU. 2018).

Los productos de PCR (500 y 900pb, respectivamente) obtenidos en la amplificación se separaron mediante electroforesis (95 voltios por 60 minutos) en gel de agarosa 1,5\% y visualizados mediante luz UV (Cornejo Romero et al. 2014). Los amplicones fueron secuenciados mediante el método de Sanger por Macrogen (Seúl, Corea del Sur).

Las secuencias consenso se alinearon mediante la herramienta ClustalW, perteneciente al programa MEGA-X (Kumar et al. 2018). Posteriormente, estas secuencias se compararon con aquellas depositadas en la base de datos Mycobank y, a través de la herramienta BLAST (Basic Local Alignment Search Tool) de GenBank (NCBI), para determinar el género y la especie de los hongos aislados.

\section{Postulados de Koch}

Las plántulas de uvilla sanas, de 15 días de edad, fueron proporcionadas porTerrafertil (Tabacundo, Pichincha). Estas se sembraron en tarrinas con el sustrato comercial de vermiculita PRO-MIX GPX (PRO MIX, Quakertown, Pennsylvania, EE. UU. 2012) y se mantuvieron en un invernadero con condiciones controladas de temperatura dentro de un rango de $15-23{ }^{\circ} \mathrm{C}$ y un porcentaje de humedad entre 70-80\% (Crosley et al. 2019).

Para la preparación del inóculo se propagaron, previamente, de forma individual, las cuatro cepas de Cercospora sp. en 12 cajas Petri conteniendo el medio CA. Estas fueron incubadas a 25 ${ }^{\circ} \mathrm{C}$ con fotoperiodo de 12h/12h por tres semanas (Rooney-Latham et al. 2011). A partir de estos cultivos, se procedió de dos maneras. En el primer caso, se colocaron $5 \mathrm{~mL}$ de agua estéril y se removieron las esporas superficiales de la colonia fúngica con la ayuda de un asa de Drigalsky. La suspensión obtenida se diluyó en una solución acuosa de polisorbato 80 al 0,1\%, hasta obtener una concentración de $1 \times 10^{4}$ conidias/mL (Caesar et al. 2009), misma que fue confirmada 
mediante recuento en cámara de Neubauer (Aguilar- Ulloa et al. 2015). En el segundo método se utilizaron discos miceliales de $5 \mathrm{~mm}$ de diámetro, obtenidos a partir de los cultivos del hongo en CA (Bobev et al. 2009; Mukhtar et al. 2019).

La inoculación en plantas, de aproximadamente cinco semanas de edad, se realizó por triplicado para cada cepa seleccionada y modalidad de inoculación (Bobev et al. 2009). De forma previa a la inoculación de las cepas fitopatógenas, bajo las dos modalidades, se realizaron pequeñas laceraciones con una aguja de $6 \mathrm{~mm}$ en las hojas de 24 plantas, previamente desinfectadas con alcohol etílico 70\% (Milosavljević et al., 2014b). En el primer método, se roció la suspensión obtenida previamente $\left(1 \times 10^{4}\right.$ conidias/ $\left.\mathrm{mL}\right)$ hasta la escorrentía; mientras que en el segundo método se colocaron, al menos, tres tampones miceliales directamente sobre cada hoja. También se utilizaron tres controles negativos en los cuales se roció agua estéril. Todas las plantas se mantuvieron en cámara húmeda durante 72 horas y, posteriormente, se transfirieron a un invernadero, donde se mantuvieron en condiciones de luz/oscuridad de $12 / 12 \mathrm{~h}$ a $25^{\circ} \mathrm{C}$ y $80 \%$ de humedad (Marin et al. 2020).

Diariamente, se evaluó la ocurrencia de cambios y la aparición de sintomatología característica de la mancha foliar por Cercospora sp. en las hojas inoculadas y se reaisló el patógeno, mediante la metodología arriba descrita, para su posterior identificación molecular con los primers ITS 1 e ITS 4 utilizando el protocolo descrito anteriormente (Soylu et al. 2003). Se utilizó la región ITS para la identificación de cepas en postulados de Koch, debido a la disponibilidad inmediata de los cebadores para la amplificación de esta región. Sin embargo, lo ideal sería identificar las cepas tanto con la región ITS como la región TEF-1 a para obtener resultados más precisos.

\section{Resultados}

Aislamiento y caracterización fenotípica de Cercospora spp.

Los síntomas característicos de la infección por Cercospora spp. en las hojas de uvilla se presentaron como manchas necróticas de forma circular o irregular, con un centro gris blanquecino, un marcado borde de color marrón oscuro y un pequeño halo de color marrón claro (Figura 1). A partir de las muestras procesadas, se obtuvieron cuatro aislados fúngicos que coincidieron con las características macroscópicas de Cercospora spp. (Tabla 1).

Tabla 1. Cepas obtenidas en cada localidad muestreada entre enero 2020- enero 2021

\begin{tabular}{ccccc}
\hline Provincia & Localidad & Georreferencia & $\begin{array}{c}\text { Mes de } \\
\text { muestreo }\end{array}$ & Código de cepa \\
\hline Pichincha & San José de & $00^{\circ} 16^{\prime} 52.2^{\prime \prime} \mathrm{N}$ & Enero & - \\
& Minas & $\begin{array}{c}078^{\circ} 21^{\prime} 03.8^{\prime \prime} \mathrm{W} \\
0^{\circ} 17^{\prime} 44.352^{\prime \prime} \mathrm{S}\end{array}$ & & ET-41 \\
& & & Noviembre & ET-22 \\
Pichincha & El Tingo & $78^{\circ} 26^{\prime} 51.682^{\prime \prime} \mathrm{W}$ & & ET-24 \\
& & & & ET-81 \\
Pichincha & Aloasí & $0^{\circ} 30^{\prime} 8.679^{\prime \prime} \mathrm{S}$ & Diciembre & - \\
& & $78^{\circ} 36^{\prime} 48.36^{\prime \prime} \mathrm{W}$ & & - \\
Imbabura & Huchinguero/ & $0^{\circ} 15^{\prime} 25.279^{\prime \prime} \mathrm{N}$ & Enero & - \\
& Alesochopa & $78^{\circ} 20^{\prime} 22.372^{\prime \prime} \mathrm{W}$ & & - \\
Imbabura & Moraspungo & $0^{\circ} 16^{\prime} 31.742^{\prime \prime} \mathrm{N}$ & Enero & \\
& & $78^{\circ} 21^{\prime} 5.493 \mathrm{~W}$ & & \\
Imbabura & Cumbasconde & $00^{\circ} 15^{\prime} 45.0^{\prime \prime} \mathrm{N}$ & Enero & \\
\hline
\end{tabular}

Los códigos ubicados en la parte derecha de la tabla pertenecen a la codificación interna del laboratorio 


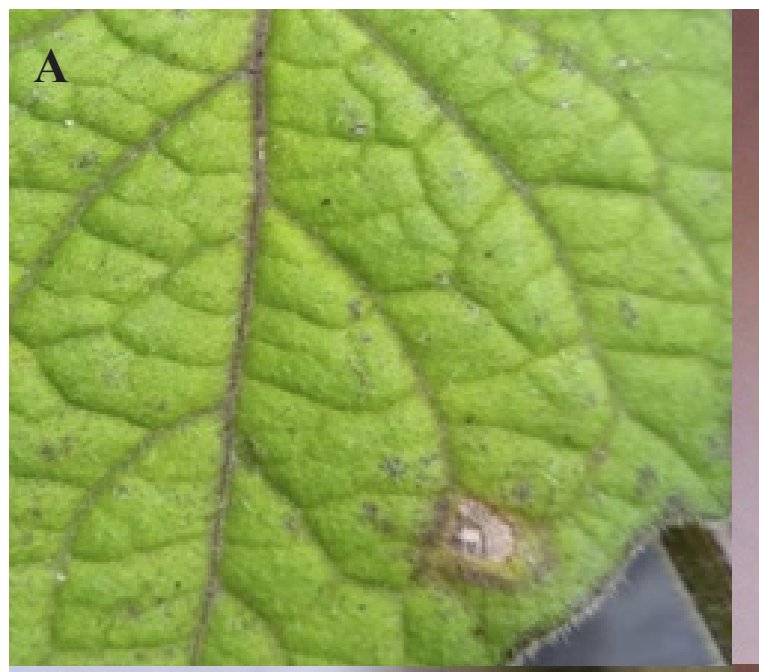

\section{B}

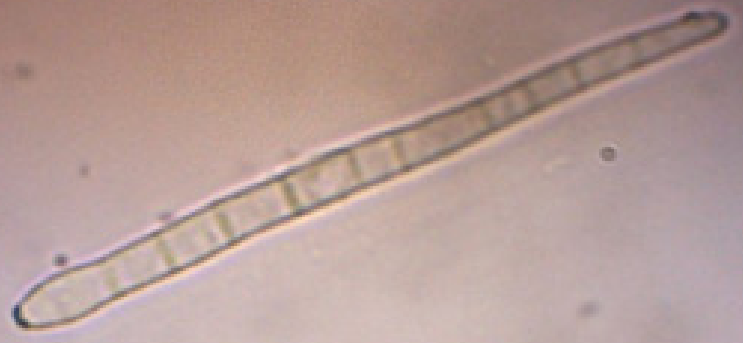

\section{C}

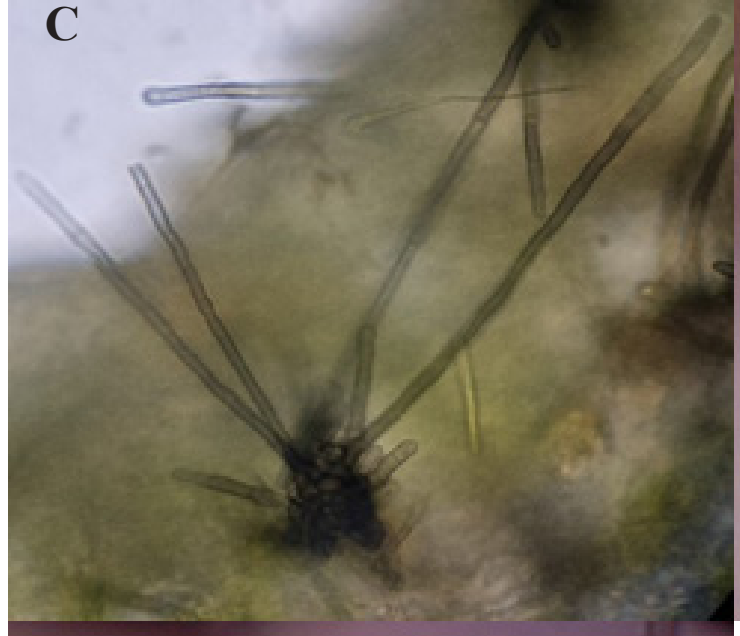

\section{D}
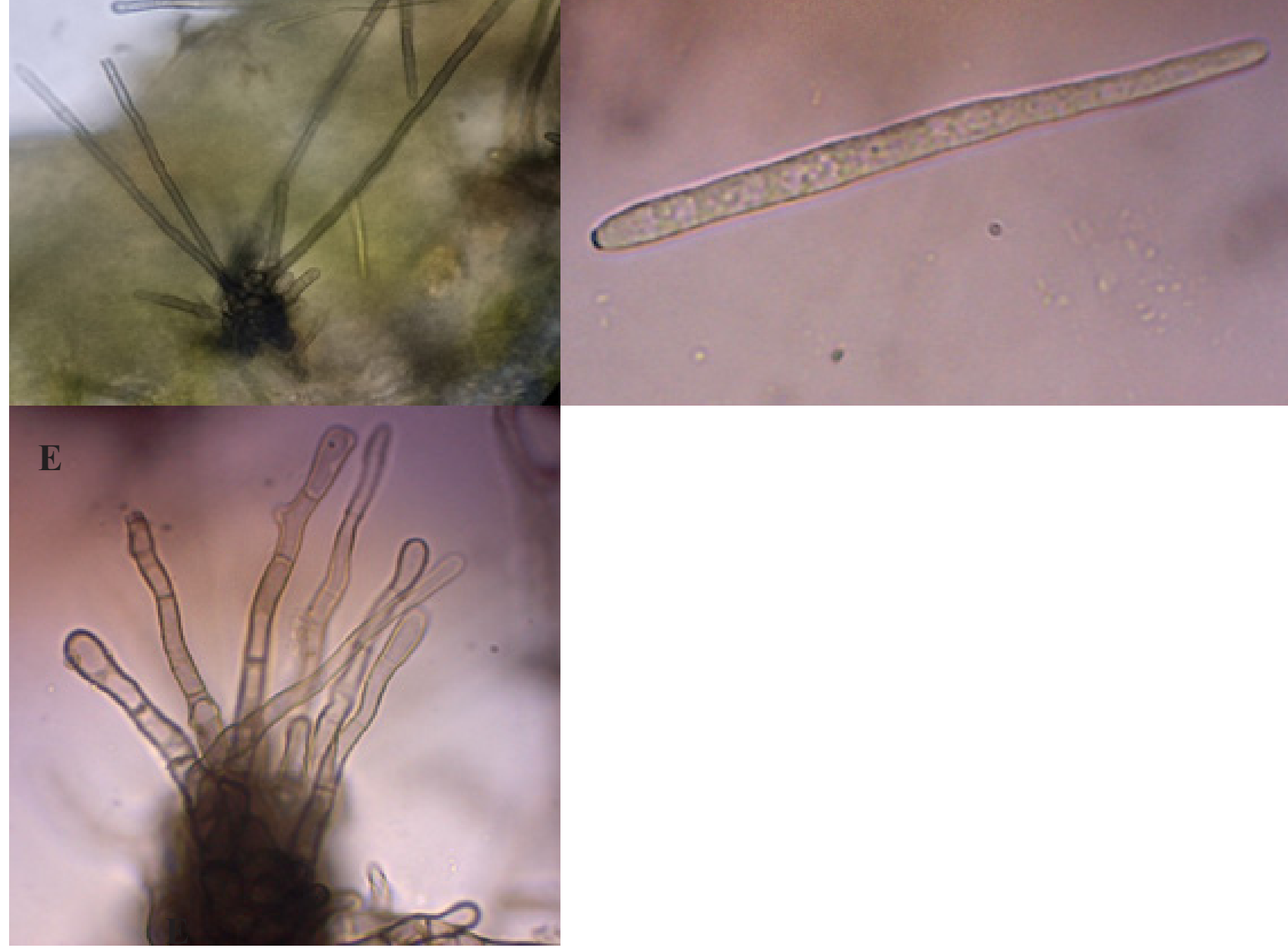

Figura 1. A) Mancha necrótica característica de Cercospora spp. en hoja de uvilla. Observación microscópica de las estructuras de Cercospora spp. en Agar zanahoria (CA, por sus siglas en inglés) después de 10 días. B) Conidio con septos; C- E) Fascículos de conidióforos; D) Conidio sin septos (Aumento total: 400x). 
Debido al crecimiento lento del hongo, las características macroscópicas en los medios PDA, MEA y CA se evaluaron después de tres semanas de incubación. En el medio PDA, las colonias presentaron una forma irregular, bordes erosionados, micelio aéreo moderado, presencia de exudados; con un color blanco en el centro de la colonia, seguido de un anillo irregular color verde oliváceo y, finalmente, un borde blanco grisáceo. En el reverso de las colonias se observó un color completamente negro (ET-22, ET-24 y ET-41), mientras que ET-81 presentó un color negro con borde negro azulado (Figura 2). Por otra parte, las colonias desarrolladas en MEA presentaron una forma circular, elevación plana, micelio aéreo moderado, borde liso (ET-81 y ET-22) o borde irregular (ET-24 y ET-41), centro gris oliváceo o gris blanquecino con borde negro blanquecino y una tonalidad amarillo-verdosa en la periferia. El aislamiento ET-41 difirió del resto, ya que en el borde no presentó coloración amarilla y, en su lugar, presentó una tonalidad blanca. En el reverso, se observó un color negro en el centro con un anillo negro grisáceo y un ligero color amarillo (Figura no presentada).

Por último, en CA la forma de las colonias fue irregular o circular, colonia elevada, bordes bien definidos y micelio algodonoso de color marrón oscuro a negro con una capa de color gris blanquecino encima. En el reverso, se presentó una coloración negra en todas las colonias (Figura 2).

La descripción microscópica se realizó a partir de un cultivo en agar zanahoria de 20 días. Se observaron entre 3 y 17 conidióforos agrupados en fascículos sueltos. Los conidióforos filiformes, rectos o ligeramente curvados presentaron color marrón claro y contenían entre 2 y 4 septos (Figura 1). Los conidios se presentaron de forma aislada, fueron hialinos, rectos o curvados, más anchos en el centro y en algunos casos con forma de aguja en uno de los extremos; se presentaron entre 0 y 14 septos (Figura 1). Las mediciones de los conidióforos y los conidios realizadas se presentan en la Tabla 2.

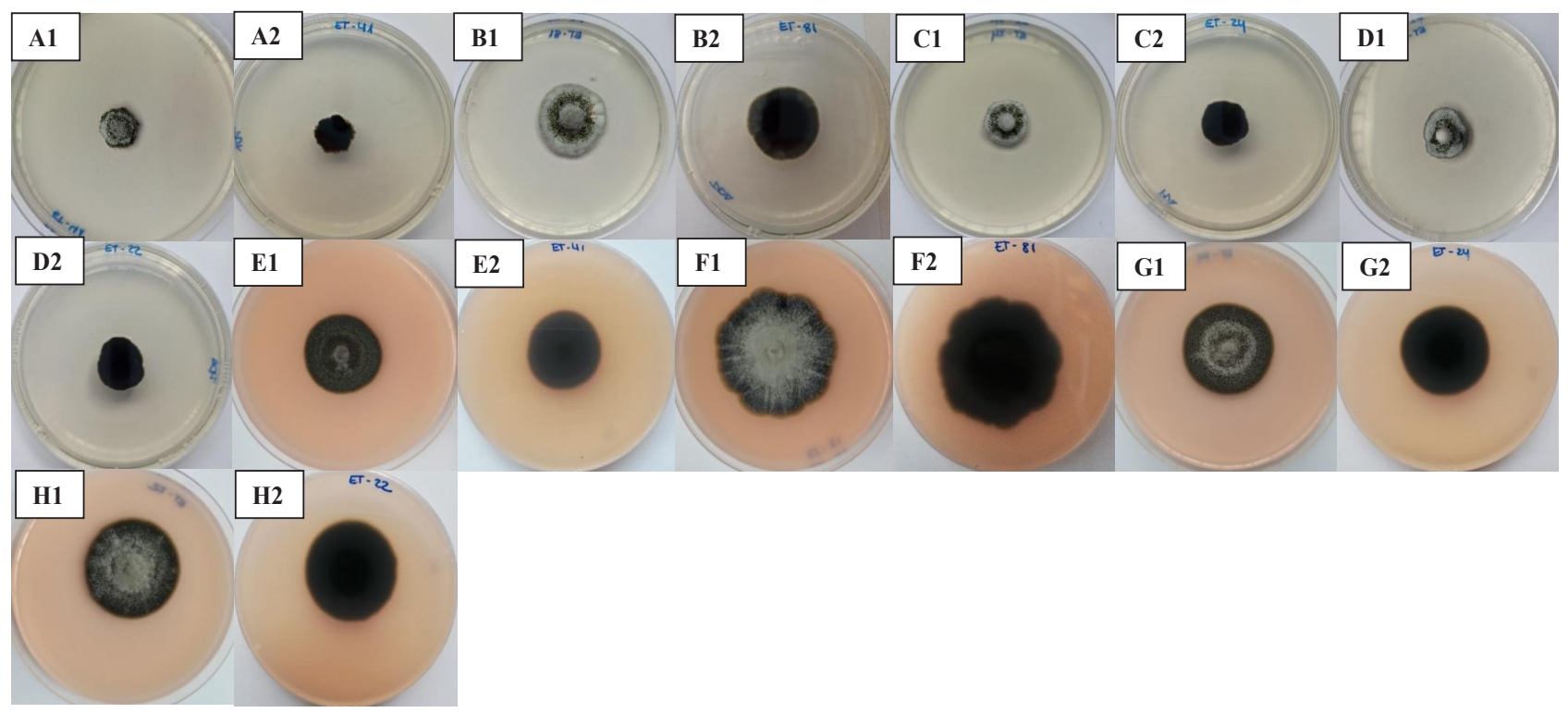

Figura 2. Observación macroscópica de los aislados de Cercospora spp. después de 3 semanas de crecimiento. 1) Anverso; 2) Reverso; A-D) Colonias en agar papa dextrosa (PDA, por sus siglas en inglés); E-H) Colonias en agar zanahoria (CA, por sus siglas en inglés. 
Tabla 2. Tamaño de las estructuras microscópicas (conidios y conidióforos) después de 20 días de crecimiento.

\begin{tabular}{ccccc}
\hline Código de & \multicolumn{2}{c}{ Conidióforos } & \multicolumn{2}{c}{ Conidios } \\
\cline { 2 - 5 } cepa & Largo $(\mu \mathrm{m})$ & Ancho $(\mu \mathrm{m})$ & Largo $(\mu \mathrm{m})$ & Ancho $(\mu \mathrm{m})$ \\
\hline ET-41 & $56,3-103,9$ & $2,9-5$ & $36.7-171.7$ & $3.0-5.1$ \\
ET-22 & $33,3-103,8$ & $2,2-5,2$ & $39.2-138.7$ & $2.3-4.2$ \\
ET-24 & $37,1-100,3$ & $3,6-4,4$ & $49.4-144.3$ & $2.9-4.4$ \\
ET-81 & $37,9-66,2$ & $2,7-3,9$ & $33.3-97.6$ & $2.6-4.3$ \\
\hline
\end{tabular}

$\mu \mathrm{m}$ : micrómetros; Número de estructuras medidas de conidióforos: 5 ;

Número de estructuras medidas de conidios: 25

\section{Identificación molecular}

Los amplicones obtenidos mediante PCR, a partir de cuatro aislados, correspondientes a las regiones ITS y TEF-1a, tuvieron un tamaño aproximado de 500 y 900 pb, respectivamente.

Las secuencias consenso obtenidas a partir de la secuenciación y alineamiento del gen ITS, resultaron en la identificación del género Cercospora, debido a que se observó un porcentaje de similitud $\geq 99 \%$, de manera simultánea, con diferentes especies de Cercospora spp. (Tabla 3); mientras que las secuencias obtenidas con el gen Factor de elongación, resultaron en la identificación de Cercospora beticola con un porcentaje $\geq 98 \%$ de similitud y $\geq 99 \%$ de cobertura, al menos, en una de las bases de datos consultadas (Tabla 3).

\section{Postulados de Koch}

Las cuatro cepas inoculadas, individualmente, en plantas de uvilla presentaron sintomatología característica de la mancha foliar por Cercospora spp. En la Tabla 4 se describe la presencia de síntomas de forma semicualitativa. Los primeros síntomas se evidenciaron 12 días después de la inoculación. Estos se presentaron como pequeñas manchas irregulares y blanquecinas alrededor de las heridas (Figura 3). Después de 7 días de la aparición de los primeros síntomas, las manchas se agrandaron y se evidenciaron manchas con un centro de color marrón claro, borde marrón oscuro y un halo verde grisáceo o marrón (Figura 3). Adicionalmente, se presentó una defoliación prematura y clorosis en todas las plantas, mientras que el control negativo no presentó cambios visibles. Por otro lado, el tratamiento con discos miceliales resultó en la ocurrencia de 10 a 15 manchas necróticas por hoja, mientras que el tratamiento de aspersión con esporas condujo a la formación de 2-4 manchas necróticas por hoja. En el aislamiento del patógeno, a partir de las plantas infectadas, se identificaron las cuatro cepas por medio de métodos moleculares; no obstante, únicamente, se logró llegar a nivel de género debido a que la similitud fue de 100\% con diferentes especies. Así, se determinó que el causante de los síntomas fue Cercospora sp.

\section{Discusión}

El género Cercospora incluye una gran cantidad de especies consideradas importantes patógenos de plantas, las cuales causan graves problemas económicos debido a su distribución mundial y la carencia de mecanismos eficientes de resistencia por parte de los hospedadores (Daub et al. 2005; Park et al. 2020). Este hongo es considerado un importante patógeno de la uvilla en Colombia, donde se ha observado que provoca manchas necróticas en las hojas y el capacho causando pérdidas en los cultivos (Fischer et al. 2014). Adicionalmente, la mancha foliar puede conducir a una defoliación total cuando la enfermedad no es controlada a tiempo; por lo que se le atribuye una gran importancia económica (Shahzady et al. 2017). En Ecuador, se han reportado síntomas característicos de esta enfermedad en diferentes localidades, pero no se han realizado los estudios necesarios para su correcta identificación y reporte (A. Jarrín, comunicación personal, 16 diciembre 2020). En este estudio, se lograron identificar cuatro cepas de Cercospora spp. en la Sierra norte del Ecuador. A pesar de que se realizaron muestreos en distintas localidades, la enfermedad solo pudo encontrarse en la localidad de El Tingo, Pichincha. Es posible que esto se deba a que ciertas localidades no presentaron la temperatura y humedad necesaria (24-27 ${ }^{\circ} \mathrm{C} y \geq 90 \%$ de humedad) para el desarrollo de la enfermedad, durante los 
Tabla 3. Identificación molecular en base a la comparación de secuencias de la región ITS y TEF obtenidas de las cepas con las bases de datos NCBI y Mycobank.

\begin{tabular}{|c|c|c|c|c|c|}
\hline $\begin{array}{c}\text { Código de la } \\
\text { cepa }\end{array}$ & $\begin{array}{c}\text { Región de } \\
\text { ADN }\end{array}$ & $\begin{array}{c}\text { Número de acceso de } \\
\text { referencia }\end{array}$ & Microorganismo & $\begin{array}{c}\text { Porcentaje de } \\
\text { similitud (\%) }\end{array}$ & $\begin{array}{l}\text { Porcentaje de } \\
\text { cobertura (\%) }\end{array}$ \\
\hline \multirow{8}{*}{ ET-41 } & \multirow{6}{*}{ ITS } & MZ047502.1 (GenBank) & Cercospora sp. & 99,32 & 100 \\
\hline & & MW581369.1 (GenBank) & Cercospora beticola & 99,32 & 100 \\
\hline & & MF681087 (Mycobank) & Cercospora beticola & 99,32 & 100 \\
\hline & & CBS 140164 (Mycobank) & $\begin{array}{l}\text { Cercospora } \\
\text { glycinicola }\end{array}$ & 99,32 & 100 \\
\hline & & MF681101 (Mycobank) & Cercospora sp. & 99,32 & 100 \\
\hline & & MF681072 (Mycobank) & Cercospora apii & 99,32 & 100 \\
\hline & \multirow{2}{*}{ TEF-1 $\alpha$} & $\begin{array}{l}\text { XM_023594009.1 } \\
\text { (GenBank) }\end{array}$ & Cercospora beticola & 98,97 & 100 \\
\hline & & CBS 116456 (Mycobank) & Cercospora beticola & 98,77 & 100 \\
\hline \multirow{9}{*}{ ET-22 } & \multirow{7}{*}{ ITS } & JX143616.1 (GenBank) & $\begin{array}{l}\text { Cercospora cf. } \\
\text { ipomoeae }\end{array}$ & 100 & 100 \\
\hline & & AY840540.1 (GenBank) & Cercospora apiicola & 100 & 100 \\
\hline & & MW581361.1 (GenBank) & Cercospora beticola & 100 & 100 \\
\hline & & CBS 140164 (Mycobank) & $\begin{array}{l}\text { Cercospora } \\
\text { glycinicola }\end{array}$ & 100 & 100 \\
\hline & & JX143590 (Mycobank) & Cercospora delaire & 100 & 100 \\
\hline & & JX143616 (Mycobank) & Cercospora sp. & 100 & 100 \\
\hline & & AY840540 (Mycobank) & Cercospora apiicola & 100 & 100 \\
\hline & \multirow{2}{*}{ TEF-1 $\alpha$} & $\begin{array}{l}\text { XM_023594009.1 } \\
\text { (GenBank) }\end{array}$ & Cercospora beticola & 98,2 & 100 \\
\hline & & CBS 116456 (Mycobank) & Cercospora beticola & 98,19 & 99,46 \\
\hline \multirow{8}{*}{ ET-24 } & \multirow{6}{*}{ ITS } & JX143616.1 (GenBank) & $\begin{array}{l}\text { Cercospora cf. } \\
\text { ipomoeae }\end{array}$ & 100 & 100 \\
\hline & & MK752901.1 (GenBank) & Cercospora nicotinae & 100 & 100 \\
\hline & & MK318663.1 (GenBank) & Cercospora beticola & 100 & 100 \\
\hline & & MF681101 (Mycobank) & Cercospora sp. & 100 & 100 \\
\hline & & MF681092 (Mycobank) & Cercospora beticola & 100 & 100 \\
\hline & & MF681072 (Mycobank) & Cercospora apii & 100 & 100 \\
\hline & \multirow{2}{*}{ TEF-1 $\alpha$} & $\begin{array}{l}\text { XM_023594009.1 } \\
\text { (GenBank) }\end{array}$ & Cercospora beticola & 98,24 & 99 \\
\hline & & CBS 116456 (Mycobank) & Cercospora beticola & 98,43 & 99,61 \\
\hline \multirow{10}{*}{$\mathrm{ET}-81$} & \multirow{8}{*}{ ITS } & MF681169.1 (GenBank) & Cercospora beticola & 100 & 100 \\
\hline & & MT626618.1 (GenBank) & Cercospora sp. & 100 & 100 \\
\hline & & MK989498.1 (GenBank) & $\begin{array}{l}\text { Cercospora cf. } \\
\text { flagellaris }\end{array}$ & 100 & 100 \\
\hline & & MT338044.1 (GenBank) & $\begin{array}{l}\text { Cercospora cf. } \\
\text { sigesbeckiae }\end{array}$ & 100 & 100 \\
\hline & & MF681093 (Mycobank) & Cercospora beticola & 100 & 100 \\
\hline & & CBS 140167 (Mycobank) & Cercospora & 100 & 100 \\
\hline & & CBS 140166 (Mycobank) & Cercospora cyperina & 100 & 100 \\
\hline & & CBS 128.27 (Mycobank) & Cercospora kikuchii & 100 & 100 \\
\hline & \multirow{2}{*}{ TEF-1 $\alpha$} & $\begin{array}{l}\text { XM_023594009.1 } \\
\text { (GenBank) }\end{array}$ & Cercospora beticola & 97,93 & 99 \\
\hline & & CBS 116456 (Mycobank) & Cercospora beticola & 98,12 & 99,63 \\
\hline
\end{tabular}


meses en los que las muestras fueron recolectadas (De Lemos Cardoso et al. 2013; Rangel et al. 2020). Esta enfermedad se desarrolla frecuentemente durante el verano y debe tener una alta humedad con largos periodos de lluvia (Fischer et al. 2014; Shahzady et al. 2017).

Según Catarina (2014), los síntomas de la infección por este hongo fitopatógeno se presentan en hojas y en capachos de la uvilla como pequeñas áreas necróticas de color gris, con presencia de pequeños halos amarillos y la formación de anillos concéntricos en función del progreso de la infección en el tejido vegetal. Sin embargo, en otros casos, se presentan como lesiones irregulares con bordes definidos limitados por las nervaduras. Por el contrario, Tian et al. (2008), reportan que las lesiones necróticas provocadas por Cercospora spp. se distinguen de las causadas por el patógeno Alternaria spp. (tizón tardío) por la ausencia de anillos concéntricos. Los síntomas encontrados en este estudio coincidieron con lo reportado en el estudio de Chai et

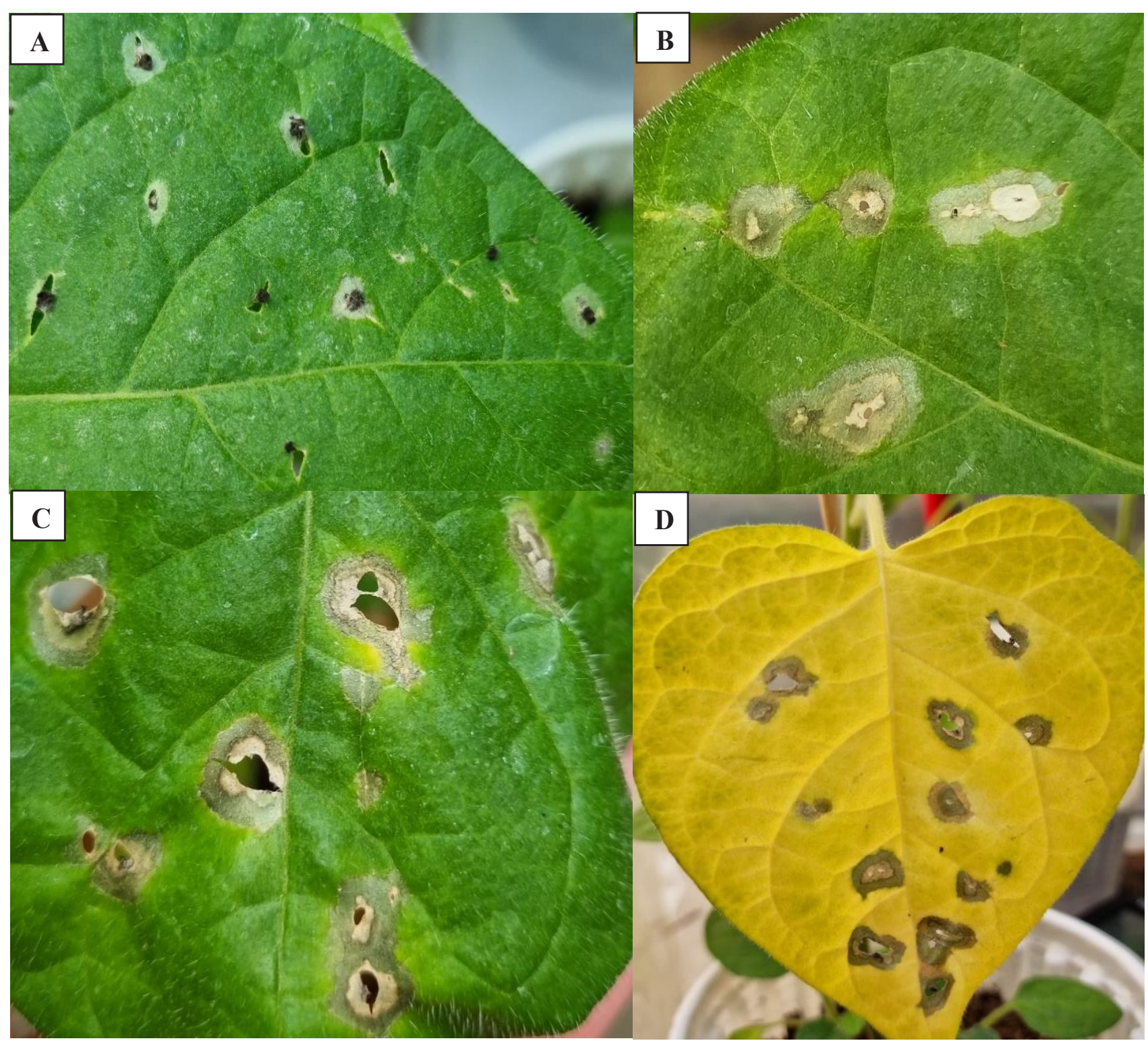

Figura 3. Lesiones producidas por Cercospora spp. en los postulados de Koch utilizando plantas de uvilla. A) Primeras lesiones producidas después de 12 días; B-C) Manchas necróticas producidas después de 19 días; D) Clorosis completa y manchas necróticas. 
Tabla 4. Determinación semicualitativa del desarrollo de síntomas de cada cepa analizada en los postulados de Koch.

\begin{tabular}{ccccc}
\hline & Cepa & \multicolumn{3}{c}{ Sintomatología } \\
\cline { 2 - 5 } & & Clorosis & $\begin{array}{c}\text { Manchas } \\
\text { irregulares }\end{array}$ & $\begin{array}{c}\text { Defoliación } \\
\text { prematura }\end{array}$ \\
\hline \multirow{2}{*}{ ET- 41 } & Tratamiento 1 & ++ & ++ & + \\
& Tratamiento 2 & +++ & +++ & ++ \\
\hline \multirow{2}{*}{ ET- 81 } & Tratamiento 1 & + & + & + \\
& Tratamiento 2 & ++ & +++ & ++ \\
\hline \multirow{2}{*}{ ET- 24 } & Tratamiento 1 & + & ++ & +++ \\
& Tratamiento 2 & +++ & +++ & + \\
\hline \multirow{2}{*}{ ET- 22 } & Tratamiento 1 & + & + & ++ \\
& Tratamiento 2 & + & ++ & + \\
\hline
\end{tabular}

al.ao, ya que las lesiones se caracterizaron por presentar un centro color blanco grisáceo, con un borde marrón oscuro seguido de un halo marrón claro o verdoso, con forma irregular y bordes bien definidos. Además, coincidieron parcialmente con lo reportado por Catarina (2004), ya que no presentaron anillos concéntricos, sino, únicamente un halo alrededor de la mancha.

Las cepas aisladas en PDA se caracterizaron por la presencia de exudados en las colonias que presentaron tonalidades blancas, verde oliva y gris con un crecimiento lento. Estos resultados son parcialmente similares a los obtenidos por Chai et al. (2021), quienes describen a las colonias en PDA como blanquecinas a grises con micelio aéreo algodonoso; mientras que en las colonias desarrolladas en MEA se observaron colores verde-grisáceo, amarillo, gris y negro blanquecino. Crous et al. (2006) reportan resultados parcialmente similares describiendo una colonia en MEA con micelio aéreo escaso, márgenes irregulares, superficie gris oliva con manchas irregulares de color blanco o gris hierro. Tanto en MEA, como en PDA, el crecimiento fue lento y no se observó el desarrollo de conidióforos ni conidios. Por otro lado, el crecimiento en CA también fue lento y dio como resultado colonias marrón oscuro y una alta producción de conidios, aunque los fascículos fueron escasos. Marin et al. (2020) llegaron a la conclusión de que el cultivo de Cercospora spp., en los medios CA y PDA + sacarosa al 6\%, conduce a una gran producción de estructuras reproductivas (conidióforos y conidios), lo que permite la correcta identificación microscópica del hongo. Adicionalmente, este género fúngico se caracteriza por tener un buen crecimiento en diferentes medios de cultivo como V8, OMA (Agar harina de avena), PDA, MEA y CA, donde las temperaturas de incubación óptimas son $24-25^{\circ} \mathrm{C}$ con un fotoperiodo de $12 \mathrm{~h} / 12 \mathrm{~h}$ (Mukthar et al. 2019).

Según Crous et al. (2007) es posible distinguir, morfológicamente, al género Cercospora spp. de otros géneros similares (Passalora, Pseudocercospora y Stenella) a través de rasgos en la estructura de las cicatrices de conidios, estructura de las hifas y presencia o ausencia de pigmentación de conidios y conidióforos (Bakhshi et al. 2012; Świderska-Burek et al. 2020). Las características microscópicas observadas del hongo en este estudio presentaron conidióforos de color marrón, rectos o ligeramente curvos, multiseptados, distribuidos en fascículos de 3 a 17 y con un tamaño de 2-5 $\mu \mathrm{m} \times$ 33-104 $\mu \mathrm{m}$, mientras que los conidios fueron hialinos, con septos de 0 a 14, rectos 0 ligeramente curvos y presentaron un tamaño de 33-175 × 2-5 $\mu \mathrm{m}$. Estas características coinciden con las reportadas en el estudio de Mukhtar et al. (2019) donde los conidióforos se presentaron de forma simple, color marrón, pero subhialinos en el ápice, rectos, con un tamaño de 4,5 a $5 \times 20$ a $100 \mu \mathrm{m}$, y cicatrices de esporas distintivas. Los conidios fueron solitarios, hialinos, filiformes, rectos o ligeramente curvados, el ápice fue obtuso o en punta, multiseptados (1 a 18) y un tamaño de 28 a $230 \times 2,5$ a 4 m. De la misma forma, Marin et al. (2020), describieron características similares a las presentadas anteriormente con pequeñas variaciones, tanto en el tamaño de los conidióforos como en el de los conidios. 
Aunque las características morfológicas son utilizadas frecuentemente para identificar aislamientos fúngicos, no es posible distinguir a las especies pertenecientes a Cercospora spp., únicamente, con base en la morfología; muchas veces, hay una superposición significativa en estas características y complica la taxonomía del género (Meghvansi et al. 2013; Park et al. 2017). Es por ello que los enfoques polifásicos, basados en ecología, morfología y estudios moleculares, se utilizan para la identificación de las especies de este género (Park et al. 2020; Świderska-Burek et al. 2020). En esta investigación se utilizaron las regiones ITS y TEF-1a, dando como resultado amplicones de 500 y 900 pb, respectivamente, en todas las cepas analizadas. Los cuatro aislados fúngicos no pudieron ser identificados a nivel de especie mediante la secuenciación de la región ITS, debido a que se obtuvo la máxima similitud con diferentes especies del género Cercospora y resultó imposible discriminar entre estas e identificar cada cepa con una especie determinada. Por lo tanto, los resultados fueron inconcluyentes al comparar las secuencias en las bases de datos GenBank y Mycobank. El espaciador transcrito interno (ITS) es un fragmento de ADN que actualmente es considerado un código de barras universal de los hongos, debido a que tiene la mayor probabilidad de identificación exitosa para una amplia gama de hongos (Schoch et al. 2012; Badotti et al. 2017) Sin embargo, Groenewald et al. (2010) sugieren que la región ITS tiene una baja capacidad para distinguir entre especies de Cercospora spp. Park et al. (2017) obtuvieron resultados similares al obtener 100\% de similitud con diferentes especies utilizando la región ITS. Estos autores tuvieron que realizar un análisis multigénico para encontrar la especie de Cercospora spp. Por lo tanto, en esta investigación se amplificó y secuenció el gen de Factor de elongación para discriminar entre especies de este género. Como resultado, se pudieron identificar los cuatro aislados como Cercospora beticola con un alto porcentaje de identidad y cobertura, tanto en la base de datos GenBank como en Mycobank. Actualmente, los códigos de barras de ADN secundarios se implementan cada vez más para grupos donde ITS no proporciona suficiente precisión (Lücking et al. 2020). En varios estudios, se ha determinado que la combinación de genes de actina (ACT), calmodulina (CAL), histona (H3), Factor de elongación (TEF 1-a) y $\beta$-tubulina (TUB) es una de las formas más efectivas para diferenciar entre las especies de Cercospora spp. (Montenegro-Calderón et al. 2011; Groenewald et al. 2013; Meghvansi et al. 2013). Adicionalmente, se han utilizado los genes ARN polimerasa II y gliceraldehído-3-fosfato deshidrogenasa que ayudan para la identificación de algunas especies del complejo C. apii (Świderska-Burek et al. 2020).

Las cuatro cepas con las que se infectaron las plantas de uvilla, en el ensayo de postulados de Koch, produjeron síntomas de la enfermedad de la mancha foliar por Cercospora beticola. Las lesiones iniciales se observaron como pequeñas manchas blanquecinas e irregulares similares a las reportadas en el estudio realizado por Mi-Jeon et al. (2020). Con el avance de las lesiones, se observó un centro gris blanquecino con un borde marrón oscuro y un halo marrón grisáceo, además de clorosis completa de la hoja y defoliación prematura. Rangel et al. (2020), describieron síntomas idénticos a los descritos en este estudio y también reportaron que, a medida que avanza la enfermedad, se produce clorosis de la hoja y las manchas pueden fusionarse para formar áreas necróticas más grandes (Marin et al. 2020). Vaghefi et al. (2017) encontraron síntomas similares y mencionaron que las lesiones necróticas se expandieron en la superficie de la hoja. Esta expansión se debe a una colonización necrotrófica para obtener nutrientes que podría matar a sus células huésped mediante toxinas (Jay et al. 2020; Andrade et al. 2021). Adicionalmente, se produce una defoliación prematura hasta del $90 \%$. Incluso, cuando la enfermedad tiene una alta severidad se puede producir la muerte de la planta (Guzmán-Piedrahita y Rivillas-Osorio 2005). El tratamiento en el que se utilizaron discos miceliales presentó mayor cantidad de manchas en menos tiempo (4 días antes). Por eso, se considera que fue más efectivo, en relación método de infección con suspensión de esporas. En ambos tratamientos, se realizó una pequeña laceración para permitir la entrada del patógeno en el tejido foliar. El daño físico provocado en las hojas ayuda a aumentar la gravedad de la enfermedad, ya que facilita la adhesión y penetración del micelio en las hojas (Subedi et al. 2019). Por último, se observó la aparición de síntomas similares a los de Cercospora sp. y se realizó el aislamiento del patógeno para su posterior secuenciación, en donde se demostró que el causante de las manchas necróticas fue el hongo fitopatógeno aislado previamente, cumpliendo así con los postulados de Koch. 
Los resultados obtenidos en este estudio son de gran importancia en la investigación sobre enfermedades foliares de la uvilla porque contribuyen al desarrollo de técnicas rápidas y precisas para el diagnóstico de la mancha foliar. Cercospora beticola es, principalmente, conocido por asociarse con la enfermedad foliar más importante y destructiva en la remolacha azucarera, provocando graves pérdidas económicas en este cultivo donde fue identificada por primera vez (Turgay et al. 2010; Zhou et al. 2014). Se caracteriza por diseminar sus esporas a través del viento, la lluvia, el riego, las salpicaduras de agua o la transferencia de insectos. Adicionalmente, los restos de plantas infectadas se consideran una fuente importante de inóculo que inicia las epidemias de la mancha foliar, ya que este hongo fitopatógeno puede persistir en forma de micelios y pseudoestromas durante un máximo de 22 meses a 3 años (Vaghefi et al. 2017). De esta manera, las esporas entran en contacto con los estomas de la hoja y dan lugar al crecimiento de hifas intercelulares (Rangel et al. 2020). En este estudio, se observaron manchas necróticas de coloración marrón que avanzaban hasta fusionarse entre ellas. Esta fase se conoce como necrotrófica y, en ella, empieza la producción de fitotoxinas y proteínas que conducen a la muerte de la célula huésped (Daub y Chung 2007). Una de las toxinas más conocidas que produce Cercospora spp. es la cercosporina. Esta toxina produce una coloración rojiza o marrón que se evidencia en la superficie del hospedero y se activa en presencia de luz y oxígeno, produciendo la muerte celular; por lo que se considera un factor de virulencia de este género (Mitchell et al. 2002). Las manchas necróticas que produce este hongo pueden expandirse por todas las hojas causando una defoliación prematura de la planta, lo que provoca pérdidas de rendimiento superiores al 50\% (De Lemos Cardoso et al. 2013). La severidad del ataque de este hongo, registrado en diferentes cultivos, ha provocado que se preste especial atención a este fitopatógeno y se realice estudios en los posibles cultivos en los que podría atacar. Al haber identificado Cercospora spp. en cultivos de uvilla en Colombia, es de gran importancia identificarlo en Ecuador también para evaluar los posibles efectos que tenga en los cultivos de uvilla del país para evitar daños a nivel de grandes plantaciones. Actualmente, se utiliza la aplicación de una mezcla de fungicidas, con diferentes modos de acción, para controlar al hongo fitopatógeno Cercospora spp. También se pueden utilizar cultivos de alto rendimiento con resistencia mejorada del hospedador y diferentes prácticas culturales como la rotación de cultivos, el manejo de malezas hospedantes y raleo de las plantas (Rangel et al.2020).

\section{Conclusiones}

Este es el primer reporte de la presencia de Cercospora beticola en cultivos de uvilla (Physalis peruviana L.) en la región centro norte de la Sierra ecuatoriana. Los postulados de Koch confirmaron que este hongo es el agente causal de la mancha foliar en cultivos de uvilla, mediante la presencia de sintomatología en plántulas sanas. Finalmente, esta investigación servirá como base para el desarrollo de métodos de identificación rápidos y eficaces de este microorganismo. También, será una contribución para próximos estudios sobre estrategias para la prevención y control de esta enfermedad, evitando así pérdidas económicas causadas a los pequeños y grandes agricultores.

\section{Agradecimientos}

Este estudio fue financiado por el proyecto titulado "Diagnóstico de las enfermedades y de plagas en cultivos comerciales de uvilla (Physalis peruviana) en el Ecuador" patrocinado por la Pontificia Universidad Católica del Ecuador.

Un agradecimiento a la empresa TERRAFERTIL y sus agricultores asociados por permitir el muestreo en diferentes parcelas y por facilitar plántulas de uvilla para el desarrollo de los postulados de Koch.

Por último, un especial agradecimiento a la empresa Golden Sweet Spirit por permitirnos realizar un muestreo en sus instalaciones ubicadas en Aloasí, Pichincha.

\section{Declaración de conflicto de intereses}

Los autores declaran no tener conflicto de intereses. 


\section{Contribución de los autores}

MP: Diseño experimental del estudio, adquisición/ colección de datos, análisis e interpretación de datos, redacción de la primera versión del manuscrito.

JY: Concepción y diseño del estudio, revisión del manuscrito y gestión de financiamiento. MMC: Análisis e interpretación de datos y revisión del manuscrito.

\section{Referencias Bibliográficas}

Agrios G. 2005. Plant Pathology. 5th. Florida (Estados Unidos): Elsevier Academic Press. 397.

Aguilar-Ulloa W, Arce-Acuña P, Galiano-Murillo F, Torres-Cruz TJ. 2015. Aislamiento de esporas y evaluación de métodos de inoculación en la producción de micorrizas en cultivos trampa. Tecnología en Marcha [Internet]. [citado 11 de junio de 2021]; 2016: 5-14. Disponible en: https:// www.scielo.sa.cr/pdf/tem/v29s3/0379-3982-tem-29-s3-5.pdf.

Andrade CCL, de Resende MLV, Moreira SI, Mathioni SM, Botelho DMS, Costa JR, Andrade ACM, Alves E. 2021. Infection process and defense response of two distinct symptoms of Cercospora leaf spot in coffee leaves. Phytoparasitica [Internet]. [citado 10 de junio de 2021]; 49: 727-737. Disponible en: 10.1007/s12600-021-00902-2.

Badotti F, Silva de Oliveira F, Garcia CF, Martins Vaz AB, Camargos Fonseca L, Alves Nahum L, Oliveira G, Góes-Neto A. 2017. Effectiveness of ITS and sub-regions as DNA barcode markers for the identification of Basidiomycota (Fungi). BMC Microbiology [Internet]. [citado 27 de junio de 2021]; 17(42): 1-12. Disponible en: 10.1186/s12866-017-0958-x.

Bakhshi M, Arzanlou M, Babai-Ahari A. 2012. Morphological and molecular characterization of Cercospora zebrina from black bindweed in Iran. Plant Pathology and Quarantine [Internet]. [citado 27 junio 2021]; 2(2): 125-130. Disponible en: 10.5943/ppq/2/2/5.

Balaguera-López HE, Martínez CA, Herrera-Arévalo A. 2014. Papel del cáliz en el comportamiento poscosecha de frutos de uchuva (Physalis peruviana L.) Ecotipo Colombia. Rev. Colomb. Cienc. Hortíc [Internet]. [10 de junio de 2021]; 8(2): 181-191. Disponible en: https://revistas.uptc.edu.co/ index.php/ciencias_horticolas/article/view/3461.

Bobev SG, Groenewald JZ, Crous PW. 2009. First Report of Cercospora beticola as a pathogen of German Statice (Goniolimon tataricum) in Bulgaria. Plant Dis [Internet]. [citado 25 junio 2021]; 93(5): 553. Disponible en: 10.1094 / PDIS-93-5-0553A.

Caesar AJ, Lartey RT, Berner DK, Souissi T. 2009. First report of leaf spot caused by Cercospora bizzozeriana on lepidium draba in the United States. Plant Dis [Internet]. [citado 25 junio 2021]; 93(1): 108. Disponible en: 10.1094/PDIS-93-1-0108B.

Catarina P. 2014. Uchuva (Physalis peruviana) fruta andina para el mundo. Alicante (España): Cebas- CSIC. 49.

Chai A, Zhao Q, Shi Y, Xie X, Li L, Li B. 2021. First report of Cercospora leaf spot caused by Cercospora cf. flagellaris on Okra in China. Plant Dis [Internet]. [citado 28 junio 2021]; 105(7): 1. Disponible en:10.1094 / PDIS-10-20-2155-PDN.

Chen MD, Lyda SD, Halliwell RS. 1979. Environmental factors influencing growth and sporulation of Cercospora Kikuchii. Mycology [Internet]. [citado 27 junio 2021]; 71(6): 1150-1157. Disponible en: 10.1080/00275514.1979.12021126.

Corrales-Bernal A, Vergara Al, Rojano B, Yahia E, Maldonado ME. 2015. Características nutricionales y antioxidantes de la uchuva colombiana (Physalys peruviana L.) en tres estadios de su maduración. ALAN [Internet]. [citado 05 de mayo de 2021]; 65(4):254-262. Disponible en: https:// www.alanrevista.org/ediciones/2015/4/art-6/\#. 
Cornejo Romero A, Serrato Díaz A, Rendón Aguilar B, Rocha Munive MG. 2014. Herramientas moleculares aplicadas en ecología: Aspectos teóricos y prácticos. 1st Ed. México DF (México): Instituto nacional de ecología y cambio climático (INECC). 27.

Crosley L, Henríquez JM, Parra F, Pacheco P, Escobar H, Parra C. 2019. Rescate del cultivo de Goldenberry (Physalis peruviana) en los Andes del norte de Chile. Idesia [Internet]. [citado 28 junio 2021]; 37(4): 115-118. Disponible en: https://www.scielo.cl/pdf/idesia/v37n4/0718-3429idesia-37-04-115.pdf.

Crous PW, Braun U, Groenewald JZ. 2007. Mycosphaerella is polyphyletic. Stud in Mycol [Internet]. [citado 25 junio 2021]; 58: 1-32. Disponible en: 10.3114/sim.2007.58.01.

Crous PW, Groenewald JZ, Groenewald M, Caldwell P, Braun U, Harrington TC. 2006. Species of Cercospora associated with grey leaf spot of maize. Stud in Mycol [Internet]. [citado 26 junio 2021]; 55: 189-197. Disponible en: 10.3114/sim.55.1.189.

Daub ME, Herrero S, Chung KR. 2005. Photoactivated perylenequinone toxins in fungal pathogenesis of plants. FEMS. Microbiology Letters [Internet]. [citado 24 junio 2021]; 252(2): $197-$ 206. Disponible em: 10.1016/j.femsle.2005.08.033.

Daub ME, Herrero S, Chung KR. 2007. Cercosporin: A photoactivated toxin in plant disease. Plant disease [Internet]. [citado 20 junio 2021]; 38: 461-490. Disponible en: 10.1094/ APSnetFeature/2007-0207.

De Lemos Cardoso RM, Dias Chaves JC, Fantin D, Lourenço Jr. V. 2013. Efficiency of green manures for Cercospora leaf spot management in coffee plants. Tropical Plant Pathology [Internet]. [citado 20 junio 2021]; 38(2): 122-127. Disponible en: https://www.scielo.br/j/tpp/a/HKyqfx8cGdvQnK4 QN4gBmHx/?lang=en.

Díaz JL, Chavez-Acuña W, Yánez J. 2019. Diversity of fungal communities inhabiting symptomatic leaves of Cape gooseberry (Physalis peruviana) in the Ecuadorian Andes Revista Ecuatoriana de medicina y ciencias biológicas [Internet]. [citado 21 junio 2021]; 40(2): 77-85. Disponible en: https://dialnet.unirioja.es/servlet/articulo?codigo=7404872.

Ebert MK, Rangel LI, Spanner RE, Taliadoros D, Wang X, Friesen TL, de Jonge R, Neubauer JD, Secor GA, Thomma BPHJ. 2020. Identification and characterization of Cercospora beticola necrosisinducing effector CbNip1. Molecular Pant Pathology [Internet]. [citado 15 mayo 2021]; 22(3): 301-316. Disponible en: 10.1111/mpp.13026.

Farrag E. 2011. First Record of Cercospora Leaf Spot Disease on Okra Plants and its Control in Egypt. Plant Pathology Journal [Internet]. [citado 18 mayo 2021]; 10(4): 175-180. Disponible en: 10.3923 / ppj.2011.175.180

Fischer G, Almanza-Merchán, PJ, Miranda D. 2014. Importancia y cultivo de la uchuva (Physalis peruviana L.). Rev. Bras. de Frutic [Internet]. [citado 18 mayo 2021]; 36(1): 1-15. Disponible en: 10.1590/0100-2945-441/13.

Fischer G, Balaguera-López HE, Magnitskiy S. 2021. Revisión de la ecofisiología de frutos andinos importantes: Solanaceae. Revista U.D.C.A Actualidad y Divulgación Científica [Internet]. [citado 22 mayo 2021]; 24(1): 1-12. Disponible en: https://revistas.udca.edu.co/index.php/ruadc/article/ view/1701/2156.

Fischer G, Melgarejo LM. 2020. The ecophysiology of cape gooseberry (Physalis peruviana L.) an Andean fruit crop. A review. Revista Colombiana de ciencias hortícolas [Internet]. [citado 20 mayo 2021]; 14(1): 76-89. Disponible en: 10.17584/rcch.2020v14i1.10893.

Giraldo GI, Cruz CD, Sanabria NR. 2017. Propiedades físicas del jugo de uchuva (Physalis peruviana) 
clarificado en función de la concentración y la temperatura. Scielo. [Internet]. [citado 15 de junio de 2021]; 28(1): 133-142. Disponible en: 10.4067/S0718-07642017000100013.

González Cabrera MV, Sánchez Herrera TE, Paredes Peralta AV. 2020. Determinación de la capacidad conservante del aceite esencial de canela sobre uvilla (Physalis peruviana) como tratamiento postcosecha. Ciencia digital [Internet]. [citado 26 mayo 2021]; 3(2.1): 210-230. Disponible en: 10.33262/concienciadigital.v3i2.1.1235.

Goodwin SB, Dunkle LD, Zismann VL. 2001. Phylogenetic Analysis of Cercospora and Mycosphaerella Based on the Internal Transcribed Spacer Region of Ribosomal DNA. Ecology and Population Biology [Internet]. [citado 26 junio 2021]; 91 (7): 648-658. Disponible en: https:// pubmed.ncbi.nlm.nih.gov/18942994/.

Groenewald M, Groenewald JZ, Crous PW. 2005. Distinct species exist within the Cercospora apii Morphotype. Phytopathology [Internet]. [citado 02 junio 2021]; 95(8): 951. Disponible en: 951. 10.1094 / PHYTO-95-0951.

Groenewald JZ, Groenewald M, Braun U, Crous PW. 2010. Cercospora speciation and Host range. En: Lartey RT, Weiland JJ, Panella L, Crous PW, Windels CE, editores. Cercospora leaf spot of sugar beet and related species. Minnesota (EU): APS Press. 21-37.

Groenewald JZ, Nakashima C, Nishikawa J, Shin H-D, Park J-H, Jama AN, Groenewald M, Braun U, Crous PW. 2013. Species concepts in Cercospora: spotting the weeds among the roses. Stud Mycol [Internet]. [citado 15 junio 2021]; 75(1): 115-170. Disponible en: https://doi.org/10.3114/ sim0012.

Guzmán-Piedrahita OA, Rivillas- Osorio CA. 2005. Producción in vitro de conidios de Cercospora coffeicola. Cenicafé [Internet]. [citado 15 junio 2021]; 56(1): 67-77. Disponible en: https://www. cenicafe.org/es/publications/arc056\%2801\%29067-078.pdf.

Jay S, Comar A, Benicio R, Beauvois J, Dutartre D, Daubige G, Li W, Labrosse S, Thomas S, Henry $\mathrm{N}$, et al. 2020. Scoring Cercospora Leaf Spot on Sugar Beet: Comparison of UGV and UAV Phenotyping Systems. Plant Phenomics [Internet]. [citado 03 junio 2021]; 2020: 1-18. Disponible en: 10.34133/2020/9452123.

Kumar S, Stecher G, Li M, Knyaz C, Tamura K. 2018. MEGA X: Molecular evolutionary genetics analysis across computing platforms. Molecular Biology and Evolution [Internet]. [citado 14 junio 2021]; 35(6): 1547-1549. Disponible en: 10.1093 / molbev / msy096.

López-Jácome LE, Hernández-Durán M, Colín-Castro CA, Ortega-Peña S, Cerón-González G, Franco-Cendejas R. 2014. Las tinciones básicas en el laboratorio de microbiología. Mediagraphic [Internet]. [citado 20 junio 2021]; 3(1): 10-18. Disponible en: https://www.medigraphic.com/ pdfs/invdis/ir-2014/ir141b.pdf.

López-Sandoval JA, Morales-Rosales EJ, Vibrans H, Morales-Morales EJ. 2018. Tasa de asimilación neta y rendimiento de Physalis bajo cultivo en dos localidades. Redalyc [Internet]. [citado 18 junio 2021]; 41(2): 187-197. Disponible en: https://www.redalyc.org/journal/610/61059020010/ $\mathrm{html} /$.

Lücking R, Aime MC, Schoch CL. 2020. Unambiguous identification of fungi: where do we stand and how accurate and precise is fungal DNA barcoding?. IMA Fungus [Internet]. [citado 21 mayo 2021]; 11(14): 1-32. Disponible en: 10.1186/s43008-020-00033-z.

Marin MV, Coburn J, Desaeger J, Peres NA. 2020. First report of Cercospora leaf spot caused by Cercospora cf. flagellaris on Industrial Hemp in Florida. Plant disease [Internet]. [citado 15 junio 2021]; 104(5): 1536. Disponible en: 10.1094/PDIS-11-19-2287-PDN. 
Meghvansi MK, Haneef Khan M, Gupta R, Veer V. 2013. Identification of a new species of Cercospora causing leaf spot disease in Capsicum assamicum in northeastern India. Elsevier [Internet]. [citado 26 mayo 2021]; 164(9): 894-902. Disponible en: 10.1016/j.resmic.2013.08.003.

Milosavljević A, Pfaf-Dolovac E, Mitrović M, Jović J, Toševski I, Duduk N, Trkulja N. 2014a. First report of Cercospora carotae, causal agent of Cercospora leaf spot of carrot, in Serbia. Plant Disease [Internet]. [citado 05 junio 2021]; 98(8): 1153. Disponible en: 10.1094/PDIS-08-13-0858-PDN.

Milosavljević A, Pfaf-Dolovac E, Mitrović M, Jović J, Toševski Y, Duduk N, Trkulja N. 2014b. First report of Cercospora apii, causal agent of Cercospora early blight of celery, in Serbia. Plant Disease [Internet]. [citado 26 mayo 2021]; 98(8). 1157. Disponible en: 1157. 10.1094 / PDIS-02-14-0135PDN.

Ministerio de Agricultura y Ganadería. 2020. Resumen Ejecutivo de los Diagnósticos Territoriales del Sector Agrario [Internet]. Quito (EC): Ministerio de Agricultura y Ganadería; [citado 2021 mayo 17]. Disponible en: https://www.agricultura.gob.ec/wp-content/uploads/2020/08/ResumenEjecutivo-Diagn\%C3\%B3sticos-Territoriales-del-Sector-Agrario_14-08-2020-1_compressed.pdf.

Mitchell TK, Chilton WS, Daub ME. 2002. Biodegradation of the Polyketide Toxin Cercosporin. Appl Environ Microbiol [Internet]. [citado 22 mayo 2021]; 68(9): 4173-4181. Disponible en: 10.1128/AEM.68.9.4173-4181.2002.

Montenegro-Calderón JG, Martínez Álvarez JA, Vieyra-Hernández, MT, Rangel-Macías LI, RazzoSoria T, Chávez-Herrera R, Ponce-Noyola P, Leal-Morales CA. 2011. Molecular identification of two strains of Cercospora rodmanii isolated from water hyacinth present in Yuriria lagoon, Guanajuato, Mexico and identification of new hosts for several other strains. Fungal Biol [Internet]. [citado 16 junio 2021]; 115(11): 1151-1162. Disponible en: 10.1016/j.funbio.2011.08.001.

Mukhtar I, Khokhar I, Yan Y, Xie B. 2019. First report of Cercospora leaf spot caused by Cercospora beticola on spinach in Pakistan. Plant Disease [Internet]. [citado 06 junio 2021]; 103(7). Disponible en: 10.1094/PDIS-12-18-2274-PDN.

Nguanhom J, Cheewangkoon R, Groenewald J, Braun U, Anun C, Crous P. 2015. Taxonomy and phylogeny of Cercospora spp. from Northern Thailand. Phylotaxa [Internet]. [citado 25 mayo 2021]; 233(1): 27-48. Disponible en: 10.11646/phytotaxa.233.1.2.

Park MJ, Back CG, Park JH. 2020. Occurrence of Cercospora Leaf Spot Caused by Cercospora cf. flagellaris on Melon in Korea. Mycobiology [Internet]. [citado 05 junio 2021]; 48(5): 418-422. Disponible en: 10.1094/PDIS-11-19-2287-PDN.

Park SH, Choi IY, Lee WH, Lee KJ, Galea V, Shin HD. 2017. Identification and Characterization of Cercospora malayensis causing leaf spot on kenaf. Mycobiology [Internet]. [citado 16 junio 2021]; 45(2): 114-118. Disponible en: 10.5941 / MYCO.2017.45.2.114

Portal Frutícola. 2020. Ecuador se enfoca en Reino Unido y Europa para la expansión de uvilla [Internet]. Santiago de Chile (CL): Portal Frutícola; [citado 2021 mayo 19]. Disponible en: https:// www.portalfruticola.com/noticias/2020/08/03/ecuador-se-enfoca-en-reino-unido-y-europapara-la-expansion-de-la-uvilla/.

Pro Ecuador. 2020. Oferta de uvilla ecuatoriana en marcados potenciales [Internet]. Quito (EC): Ministerio de producción, comercio exterior, inversiones y pesca; [citado 2021 mayo 6]. Disponible en: https://www.proecuador.gob.ec/oferta-de-uvilla-ecuatoriana-en-mercadospotenciales-2020/.

PRO MIX. 2012. PRO- MIX PGX [Internet]. Quakertown (EU): PRO MIX; [citado15 junio 2021]. Disponible en: https://www.pthorticulture.com/media/3815/sds-promix-pgx-gtx.pdf. 
Promega. 2018. GoTaq ${ }^{\oplus}$ Green Master Mix [Internet]. Wisconsin (EU): Promega Corporation; [citado 02 mayo 2021]. Disponible en: https://worldwide.promega.com/products/pcr/taqpolymerase/gotaq-master-mixes/?catNum=M7122.

Promega. 2019. Wizard Genomic DNA purification kit [Internet]. Wisconsin (EU): Worldwide Promega; [citado 2021 mayo 15]. Disponible en: https://worldwide.promega.com/resources/ protocols/technical-manuals/0/wizard-genomic-dna-purification-kit-protocol/.

Rangel LI, Spanner RE, Ebert MK, Pethybridge SJ, Stukenbrock EH, De Jonge R, Secor GA, Bolton MD. 2020. Cercospora beticola: The intoxicating lifestyle of the leaf spot pathogen of sugar beet. Molecular Plant Pathology [Internet]. [citado 10 mayo 2021]; 21(8): 1020-1041. Disponible en: 10.1111/mpp.12962.

Rehner SA, Buckley E 2005. A Beauveria phylogeny inferred from nuclear ITS and EF1-a sequences: evidence for cryptic diversification and links to Cordyceps teleomorphs. Mycologia [Internet]. [citado 15 junio 2021]; 97(1): 84-98. Disponible en: 10.1080/15572536.2006.11832842.

Rengifo-Guzmán HG, Leguizamón-Caicedo JE, Riaño-Herrera NM. 2002. Algunos aspectos biológicos de Cercospora coffeicola. Cenicafé [Internet]. [citado 25 junio 2021] 53(3): 169-177. Disponible en: https://www.cenicafe.org/es/publications/arc053(03)169-177.pdf.

Rooney-Latham S, Scheck HJ, Walber TM. 2011. First report of Cercospora beticola causing a leaf spot disease on Acanthus mollis in California. Plant Dis [Internet]. [citado 25 mayo 2021]; 95(2): 224. Disponible en: 10.1094/pdis-10-10-0700.

Schoch CL, Seifert KA, Huhndorf S, Robert V, Spouge JL, Levesque CA, Chen W, Fungal Barcoding Consortium. 2012. Nuclear ribosomal internal transcribed spacer (ITS) region as a universal DNA barcode marker for Fungi. PNAS [Internet]. [citado 18 junio 2021]; 109(16): 6241-6242. Disponible en: 10.1073/pnas.1117018109.

Shahzady HM, Ahmad T, Moosa A, Ahmed Khan W, Naeem I, Nasir M, Aslam Khan M, Abbas A. 2017. A general review of Cercospora leaf spot disease of mungbean and its management. International Journal of Scientific Footprints [Internet]. [citado 25 mayo 2021]; 5(2): 81-84. Disponible en: 10.22576/ijsf/sf-2017-84.

Soylu S, Soylu EM, Kurt S. 2003. First report of Cercospora leaf spot on Swiss chard caused by Cercospora beticola in Turkey. Plant Pathology [Internet]. [citado 27 mayo 2021]; 52: 804. Disponible en: https://www.ndrs.org.uk/article.php?id=007026.

Subedi U, Acharya S, Chatterton S, Thomas J, Friebel D. 2019. Techniques for screening Cercospora leaf spot resistant fenugreek genotypes. Canadian Journal of Plant Science [Internet]. [citado 16 junio 2021]; 99(3). Disponible en: 10.1139/cjps-2018-0247.

Świderska-Burek U, Daub ME, Thomas E, Jaszek M, Pawlik A, Janusz G. 2020. Phytopathogenic Cercosporoid Fungi-From Taxonomy to Modern Biochemistry and Molecular Biology. International Journal of Molecular Sciences [Internet]. [citado 14 junio 2021]; 21(22): 8555. Disponible en: 10.3390/ijms21228555.

Thermo Fischer Scientific [Internet]. 2009. NanoDrop 2000/2000c Spectrophotometer. Wilmington, Delaware: Thermo Fischer Scientific Inc;; [citado el 20 de mayo de 2021]. Disponible en: https://assets.thermofisher.com/TFS-Assets/CAD/manuals/NanoDrop-2000-User-ManualEN.pdf.

Tian SM, Ma P, Liu DQ, Zou MQ. (2008). First Report of Cercospora concors causing Cercospora leaf blotch of potato in Inner Mongolia, North China. Plant Dis [Internet]. [citado 24 mayo 2021]; 92(4): 654. Disponible en: 10.1094 / PDIS-92-4-0654C. 
Trillos González O, Cotes Torres JM, Medina Cano Cl, Lobo Arias M, Navas Arboleda AA. 2008. Caracterización morfológica de cuarenta y seis accesiones de uchuva (Physalis peruviana L.), en Antioquia (Colombia). Revista Brasilera de Fruticultura [Internet]. [citado 19 junio 2021]; 30(3): 708-715. Disponible en: 10.1590/S0100-29452008000300025.

Turgay EB, Bakir M, Özeren P, Katrciog `lu YZ, Maden S. 2010. Detection of pathotypes and genetic diversity of Cercospora beticola. The Plant Pathology Journal [Internet]. [citado 23 mayo 2021]; 26(4): 306-312. Disponible en: 10.5423/PPJ.2010.26.4.306.

Vaghefi N, Nelson SC, Kikkert JR, Pethybridge SJ. 2017. Genetic structure of Cercospora beticola populations on Beta vulgaris in New York and Hawaii. Sci Rep [Internet]. [citado 14 junio 2021]; 7(1726): 1-16. Disponible en: 10.1038/s41598-017-01929-4.

White TJ, Bruns T, Lee S, Taylor J. 1990. Amplification and direct sequencing of fungal ribosomal RNA genes for phylogenetics PCR protocols, a guide to methods and applications. New York (Estados Unidos): Academic Press. 315-322.

Zhou R, Kaneko S, Tanaka F, Kayamori M, Shimizu M. 2014. Disease detection of Cercospora leaf spot in sugar beet by robust template matching. Computers and Electronics in Agriculture [Internet]. [citado 15 junio 2021]; 108(2014): 58-70. Disponible en: 10.1016/j.compag.2014.07.004. 